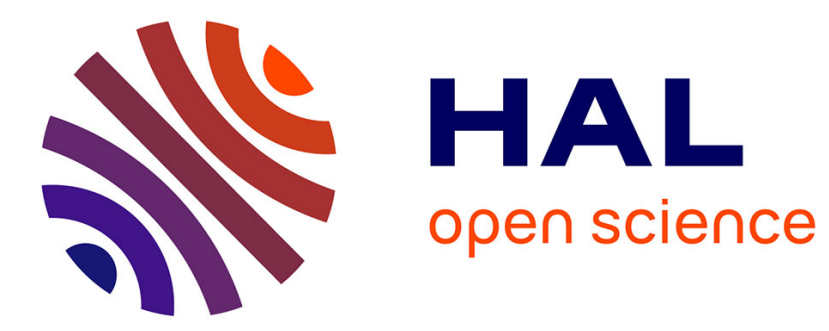

\title{
Assessment of the Impact of Split Storage within Modular Multilevel Converter
}

Florian Errigo, Laurent Chédot, Pascal Venet, Ali Sari, Piotr Dworakowski, Florent Morel

\section{To cite this version:}

Florian Errigo, Laurent Chédot, Pascal Venet, Ali Sari, Piotr Dworakowski, et al.. Assessment of the Impact of Split Storage within Modular Multilevel Converter. 45th IEEE IECON, Oct 2019, Lisbon, Portugal. pp.4785-4792, 10.1109/IECON.2019.8927698 . hal-02432358

\section{HAL Id: hal-02432358 https://hal.science/hal-02432358}

Submitted on 8 Jan 2020

HAL is a multi-disciplinary open access archive for the deposit and dissemination of scientific research documents, whether they are published or not. The documents may come from teaching and research institutions in France or abroad, or from public or private research centers.
L'archive ouverte pluridisciplinaire HAL, est destinée au dépôt et à la diffusion de documents scientifiques de niveau recherche, publiés ou non, émanant des établissements d'enseignement et de recherche français ou étrangers, des laboratoires publics ou privés. 


\title{
Assessment of the Impact of Split Storage within Modular Multilevel Converter
}

\author{
Florian Errigo ${ }^{12}$, Laurent Chédot ${ }^{1}$, Pascal Venet ${ }^{123}$, Ali Sari ${ }^{124}$ \\ Piotr Dworakowski ${ }^{15}$, Florent Morel ${ }^{16}$ \\ ${ }^{1}$ SuperGrid Institute, 23 rue Cyprian, 69611 Villeurbanne, France \\ ${ }^{2}$ Univ. Lyon, Université Claude Bernard Lyon 1, Ecole Centrale de Lyon, INSA Lyon, CNRS, Ampère, F-69000, Lyon, France \\ 3 https://orcid.org/0000-0002-2235-178X \\ 4 https://orcid.org/0000-0003-4446-7748 \\ 5 https://orcid.org/0000-0002-6893-0103 \\ 6 https://orcid.org/0000-0003-3098-7806
}

\begin{abstract}
The introduction of Renewable Energy Sources (RES) and the electricity market liberalization have pointed out the need to upgrade the current electricity transmission network. High Voltage Direct Current (HVDC) transmission system is potentially the key. Recent advances in power electronics have allowed the introduction of power converters in power system applications as the Modular Multilevel Converter (MMC). In the same perspective, grid scale Energy Storage Systems (ESSs) have broadly appeared. The dual purposing to combine both systems can provide a completely new solution. Even though each submodule (SM) within modular converter can have its own ESS, decreasing the number of energy storage submodules (ES-SMs) may be required to reduce the cost. This paper deals with the opportunities to introduce split storage into an MMC. The analysis is focused on the internal energy exchange to maintain the proper function of the converter by using circulating current. Analysis shows that, SM capacitor voltage ripple or semiconductors load are greatly influenced by additional circulating current injection. This study helps to design embedded ESSs in the converter to provide new function like ancillary services for power system operation. Finally, a simulation of an MMC with ESS confirms analytical calculations.
\end{abstract}

Index Terms-HVDC, Modular multilevel converter, Energy storage system, Topological analysis

\section{INTRODUCTION}

Energy policies are playing a more and more important role in the improvement of the power transmission network since states have gathered in a collective effort to develop green electricty [1]. A massive introduction of Renewable Energy Sources (RES) is expected in the future energy mix. Similarly, the shift from an integrated model to an unbundled model for electricity companies with the opening of the electricity market has imposed new considerations as there is no central organization responsible for the provision of the electrical energy [2]. Although competition is expected to benefit the whole economy, the complexity of the electricity market will inevitably require more interconnections to build a well connected area. The needs to upgrade the existing transmission system is stronger than ever.

HVDC transmission system has been receiving an increasingly interest for the supply of the electrical energy at high voltage over long distances [3]. The technology has gained acceptance with the Modular Multilevel Converter (MMC) milestone [4]. Thanks to its modular structure, it can easily adapt to high voltage and power levels.

The previously explained issues impose more stress on the transmission grid. Maintaining system stability is harder. Flexible mechanisms are required to cope with unforeseen outages and unpredictable demand. Energy Storage Systems (ESSs) are considered as a main enabling solution to face new challenges entailed by the ongoing transition.

In regard to the above mentioned, the association of both systems seems a promising solution. The idea to divide massive storage into smaller blocks within each submodule (SM) of a multilevel converter was initiated in [5] in a Cascaded $\mathrm{H}$ Bridge (CHB) converter. Because most of the time, multilevel converters are considered to only connect an ESS to the grid, MMC topology have been less investigated. However, the purpose to increase the attractiveness of the MMC by providing grid support in addition to power transfer function was introduced in [6] and has since then attracted much interest both in industry and academia over the last years [7][13].

It is generally assumed that all the SMs are connected to an ESS unit. However, the main advantage of the converter is that energy is stored in the SMs between the ac and dc grid. The internal stored energy can be freely controlled. This new degree of freedom allows to maintain the energy balance even with a not regular storage allocation by utilizing circulating currents. It is usually done at the cost of higher semiconductor load [14]. However no information on capacitor voltage ripple, which is prevailing to determine the size of a $\mathrm{SM}$, or simulation results have been provided. Currently, one of the few solutions for the enhancement of MMC converters for HVDC transmission was lately brought by [15] where each arm comprises only a fraction of SMs with an ESS.

To a certain extent, reducing the number of energy storage submodules (ES-SMs) require to oversize components. But it is not straightforward and some configurations permit more flexibility. The main contribution of this paper is to give an 
analysis and a simulation model of an MMC with split ESS that can be used to design a converter with storage services. For instance, the relation between the power transfer, capacitor voltage ripple and arm currents are analysed.

The outline of this paper is as follows. Section II recalls the MMC fundamentals. This is followed by an analysis on the internal power flow of the converter. A comparison among five configurations where ESS is unevenly distributed within the converter is presented in Section III. In Section IV, analytical results are validated by simulations. Finally, Section $\mathrm{V}$ concludes the presented comparison.

\section{Modular Multilevel Converter}

\section{A. Converter topology}

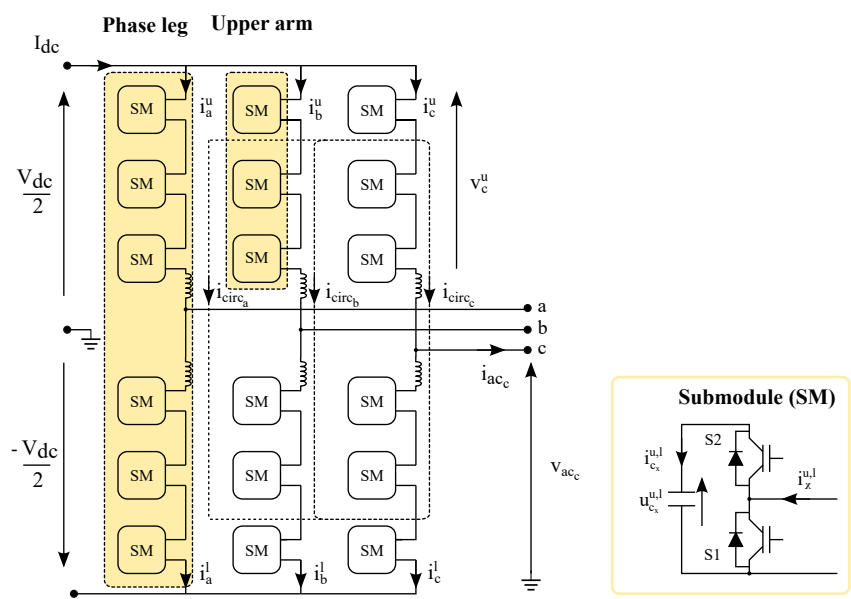

Fig. 1. Three-phase Modular Multilevel Converter topology with half bridge SM

An MMC (Fig.1) is composed of three phase legs (Subscript $a, b, c$ ), each with an upper and a lower arm (Superscript $u, l$ ). Each arm comprises a set of SMs. In this paper the most popular structure is assumed, a half-bridge cell. Each SM has two switches and a floating de capacitor. By controlling the proportion of SMs inserted or bypassed in the respective arms, it is possible to generate a controlled staircase voltage waveform at the ac output of the converter. For preliminary considerations, arm voltage and current equations are reminded in (1), (2), (3), (4). Only one MMC leg is taken into account, $x(x \in\{a, b, c\})$, because it can be easily extended to a three-phase system by adjusting the phase shift.

$$
\begin{aligned}
& i_{x}^{u}(t)=\frac{I_{d c}}{3}+\frac{\widehat{I_{a c_{x}}}}{2} \sin (\omega t-\phi)+i_{c i r c_{x}}(t) \\
& i_{x}^{l}(t)=\frac{I_{d c}}{3}-\frac{\widehat{I_{a c_{x}}}}{2} \sin (\omega t-\phi)+i_{c i r c_{x}}(t) \\
& v_{x}^{u}(t)=\frac{V_{d c}}{2}-\widehat{V_{a c_{x}}} \sin (\omega t) \\
& v_{x}^{l}(t)=\frac{V_{d c}}{2}+\widehat{V_{a c_{x}}} \sin (\omega t)
\end{aligned}
$$

Each arm conducts a dc component, $I_{d c}$, equally split from the dc side and half of the ac output current, $i_{a c}(t)$, with $\widehat{I_{a c}}$ the maximum peak value and $\phi$ the phase shift of the grid current from the grid voltage. To perform properly, an MMC needs a power balance between the dc and ac sides but also an adequate arm energy balancing. During normal operation, the internal energy is evenly shared among all the arms. But in case of unbalance, balancing currents, the so called "circulating currents" are induced, $i_{c i r c_{x}}(t)$. Those currents allow an horizontal power transfer between phase legs and a vertical power transfer within a single leg to keep the converter balanced. They are at least comprised of a dc component, $I_{\text {circ }_{x}}^{d c}$, and an ac component at the line frequency, $i_{\text {circ }}^{a c}(t)$ with $\psi$ the phase shift of the circulating current from the grid voltage, to enable power to be transferred among arms (5). They have no impact on the grids and remain internal to the converter. Consequently, the sum of the circulating currents in the three phase legs is null (6).

$$
\begin{aligned}
& i_{\text {circ }_{x}}(t)=I_{\text {circ }}^{d c}+\widehat{I_{\text {circ }}^{a c}} \sin (\omega t-\psi) \\
& i_{\text {circ }_{a}}(t)=-i_{\text {circ }}(t)-i_{\text {circ }_{c}}(t)
\end{aligned}
$$

\section{B. Internal power flow}

The ac and dc grids are coupled through arm dynamics. The arm behavior can be decomposed into two decoupled ac and dc voltage sub-systems that can be controlled independently [16]. SM capacitors are always charged/discharged with modulated $\mathrm{dc}$ and ac currents. Their voltage, $u_{c_{x}}^{u, l}(t)$, which reflects the energy stored, is permanently kept close to a reference value. Because the evolution of the arm energy depends on the power exchanged, the average power into the arm equals to zero over one period. Suggesting that SM capacitors energy will not deviate. To analyse the energy variation in the arms, the instantaneous power is given by:

$$
\begin{aligned}
p_{x}^{u}(t) & =v_{x}^{u}(t) i_{x}^{u}(t) \\
p_{x}^{l}(t) & =v_{x}^{l}(t) i_{x}^{l}(t)
\end{aligned}
$$

Substituting (1), (2), (3), (4) into (7), (8), the time average of the power in the arms are as follow:

$$
\begin{aligned}
\overline{p_{x}^{u}}= & \frac{V_{d c} I_{d c}}{6}-\frac{\widehat{V_{a c}} \widehat{I_{a c}} \cos (\phi)}{4}-\frac{\widehat{V_{a c}} \widehat{I_{c i r c_{x}}^{a c}} \cos (\psi)}{2} \\
& +\frac{V_{d c} I_{c i r c_{x}}^{d c}}{6} \\
\overline{p_{x}^{l}}= & \frac{V_{d c} I_{d c}}{6}-\frac{\widehat{V_{a c}} \widehat{I_{a c}} \cos (\phi)}{4}+\frac{\widehat{V_{a c}} \widehat{I_{\text {circ }}^{a c}} \cos (\psi)}{2} \\
& +\frac{V_{d c} I_{c i r c_{x}}^{d c}}{6}
\end{aligned}
$$

The first two terms on the right side of (9), (10), depict the power balance between the ac and dc grids. The remaining terms represent the power exchange within the converter due to the ac and the dc component of the circulating currents. 
Horizontal power transfer: The circulating current contains a dc component. It is common to each arm of an individual phase leg. So, the upper and lower arm act in the same manner by injecting (or consuming) power (9), (10). Due to (6), a power transfer between legs is feasible.

Vertical power transfer: Arm currents within a leg are in opposition of phase (1), (2). By utilizing an alternating current common to a leg, (5), a power transfer between the upper and the lower arm is possible (9), (10). The optimal power transfer is done when it is phase aligned with one of the two arms.

This freedom to control the dispersion of the internal energy allows unequal ESS integration. In this paper, if an MMC arm has energy ES-SMs, all their capacitors are connected to an ESS unit through a dc-dc converter, see Fig.2. This configuration allows a full decoupling of the energy management of the ESS from the capacitor voltage and to optimize the design of the solution. In the following section, the case where all MMC modules have an ES-SM and the cases depicted in Fig. 3 will be studied. A term $P_{E S S}^{u, l}$ must be added to (9), (10) for arms with ES-SMs. It stands for the additional average power provided into the SM capacitors of the respective arms by the ES-SMs.

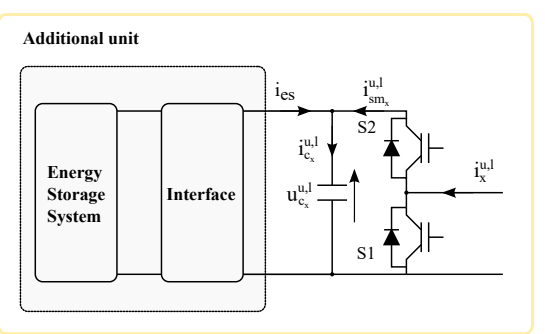

Fig. 2. Structure of an Energy Storage Submodule (ES-SM)

\section{Analysis on submodule capacitor ripples}

Since the arm currents are not identical with split ESS, the change in current imposes more stress on semiconductors [14]. Similarly, the rectified current that flows across the SM toward the capacitor, $i_{s m_{x}}^{u, l}$, will change, see Fig.2. It can be simply expressed in (11), with $m_{x}^{u, l}(t)$, the sinusoidal modulation function, and $M$ the modulation index. Note, this approach does not consider the switching contribution.

$$
\begin{aligned}
i_{s m_{x}}^{u, l}(t) & =m_{x}^{u, l}(t) i_{x}^{u, l}(t) \\
m_{x}^{u, l}(t) & =\frac{1}{2} \pm \frac{M}{2} \sin (\omega t) \\
M & =\frac{2 \widehat{V_{a c}}}{V_{d c}}
\end{aligned}
$$

Similarly, this examination considers a steady state operation mode of the converter. It supposes the circulating currents are calculated in a way that it balances the direct current necessary for the power exchange. Then, a unity power factor is assumed. By substituting (1), (2) into (11), the evolution of the current that flows towards the SM capacitors, $i_{s m_{x}}^{u, l}$, is derived. It is composed of a dc component which equals zero in steady state without any grid disturbances. Otherwise SM capacitors energy will drift. The remaining terms are intrinsic oscillations at the line frequency and twice the line frequency. For a sake of clarity, they were simplified into two trigonometric functions (12).

$$
\begin{aligned}
& \tilde{i}_{s m_{x}}^{u, l}(t)=\sqrt{\left(a_{1}^{u, l}\right)^{2}+\left(b_{1}^{u, l}\right)^{2}} \sin \left(\omega t-\arctan \left(\frac{b_{1}^{u, l}}{a_{1}^{u, l}}\right)\right) \\
& +\sqrt{\left(a_{2}^{u, l}\right)^{2}+\left(b_{2}^{u, l}\right)^{2}} \sin \left(2 \omega t-\arctan \left(\frac{b_{2}^{u, l}}{a_{2}^{u, l}}\right)\right) \\
& \tilde{i}_{s m_{x}}^{u}(t)\left\{\begin{aligned}
a_{1}^{u} & =-\frac{\widehat{I_{d c}} M}{6}+\frac{\widehat{I_{a c}} \cos (\phi)}{4}-\frac{I_{c i r c_{x}}^{d c}}{2}+\frac{\widehat{I_{c i r}^{a c}} \cos (\psi)}{2} \\
b_{1}^{u} & =\frac{\widehat{I_{a c}} \sin (\phi)}{4}+\frac{\widehat{I_{c i r c_{x}}^{a c}} \sin (\psi)}{2} \\
a_{2}^{u} & =\frac{\widehat{I_{a c}} M \sin (\phi)}{8}+\frac{\widehat{I_{c i r c_{x}}^{a c}}}{4} \sin (\psi) \\
b_{2}^{u} & =-\frac{\widehat{I_{a c}} M \cos (\phi)}{8}-\frac{\widehat{I_{c i r c_{x}}^{a c}} M \cos (\psi)}{4}
\end{aligned}\right.
\end{aligned}
$$

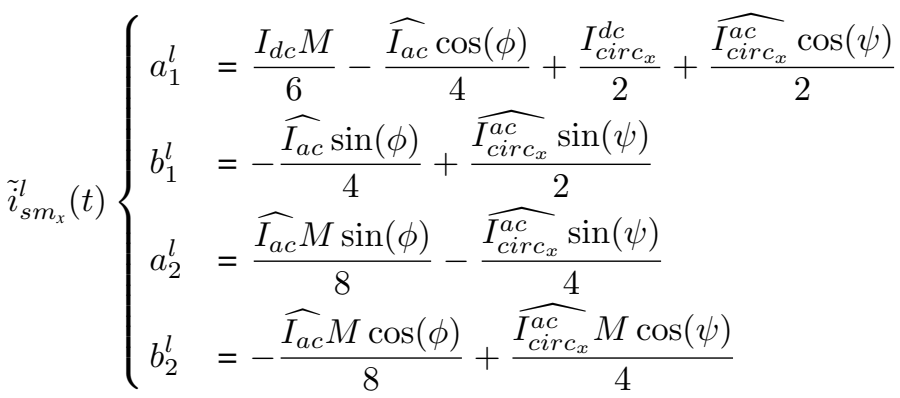

In this paper, the assumption that all the ripples are buffered by the SM capacitor is made. Consequently, the current that flows through the SM capacitors, $\tilde{i}_{c_{x}}^{u, l}$, is given as follows (13).

$$
\begin{aligned}
\tilde{i}_{s m_{x}}^{u, l}(t) & =\tilde{i}_{c_{x}}^{u, l}(t) \\
\bar{i}_{s m_{x}}^{u, l} & =i_{e s}(t)
\end{aligned}
$$

The values of the ac and dc currents can be calculated as a function of the ac and dc powers and considering the power flow within the converter (14). Then the circulating currents were deduced from (9), (10).

$$
P_{a c}=P_{d c}+P_{e s s}
$$

Because capacitor voltage ripple is a driving factor for determining the size of the SM capacitor, an estimation is provided by integrating (12). In Fig.4, capacitor current and voltage waveforms are shown during normal inverter operation. The derived equation indicated that the SMs of each arm experience various voltage ripple if an uneven power distribution occurs. 

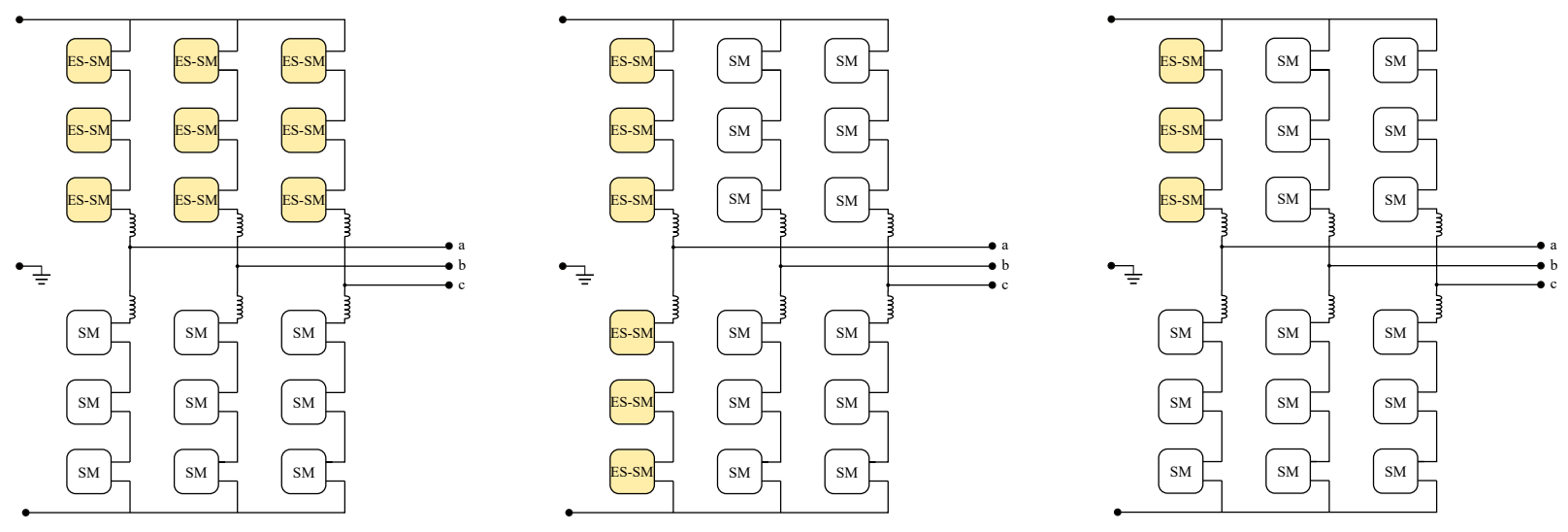

Fig. 3. MMC with ESS connected to (a) one side, (b) one leg, (c) one arm of the converter (Note an MMC with two ES-SMs legs is not depicted because is very similar to operating an MMC with one ES-SMs leg)

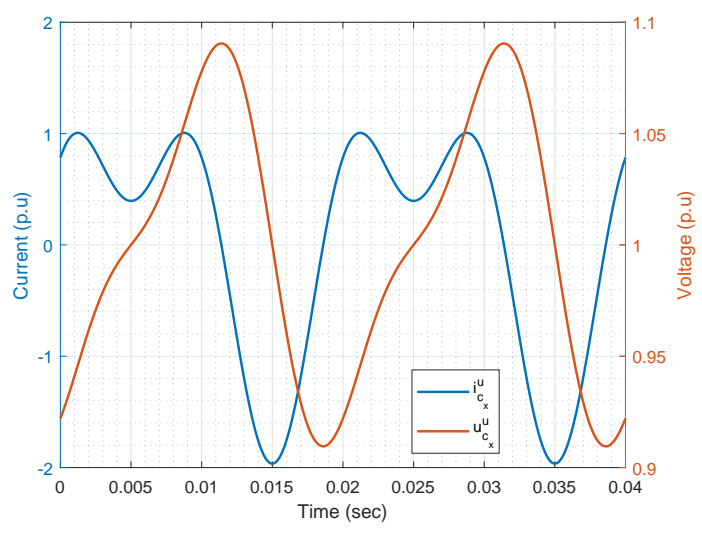

Fig. 4. Submodule capacitor current and voltage waveforms during normal inverter operation

\section{UNBALANCED STORAGE INTEGRATION}

This section provides a comparison among five configurations, where ESS is differently assigned within the MMC, using the derived relations of Section II. The values of the circulating currents are calculated using (9), (10). It investigates the impact on the arm currents and SM capacitor sizes in the arms with and without ES-SMs, see Fig.5 and Fig.6. A 1 GW converter is considered [17]. In inverter mode, the dc power is kept constant while the power injected by the ESS, $P_{e s s}$, varies from zero to the nominal power of the converter according to the deviation in $\mathrm{AC}$ power. By the same way in rectifier mode, the ac power is unchanged. A positive (reciprocally a negative) value of $P_{E S S}$ means the ES-SMs have to generate (reciprocally absorb) power.

\section{A. Integrating ESS in one or two legs}

Connecting ESS to one leg (orange lines) rather than to two legs (yellow lines) leads to higher peak and RMS currents in the phase with ES-SMs. No matter the operating point of the converter, the phases without ES-SMs have the same
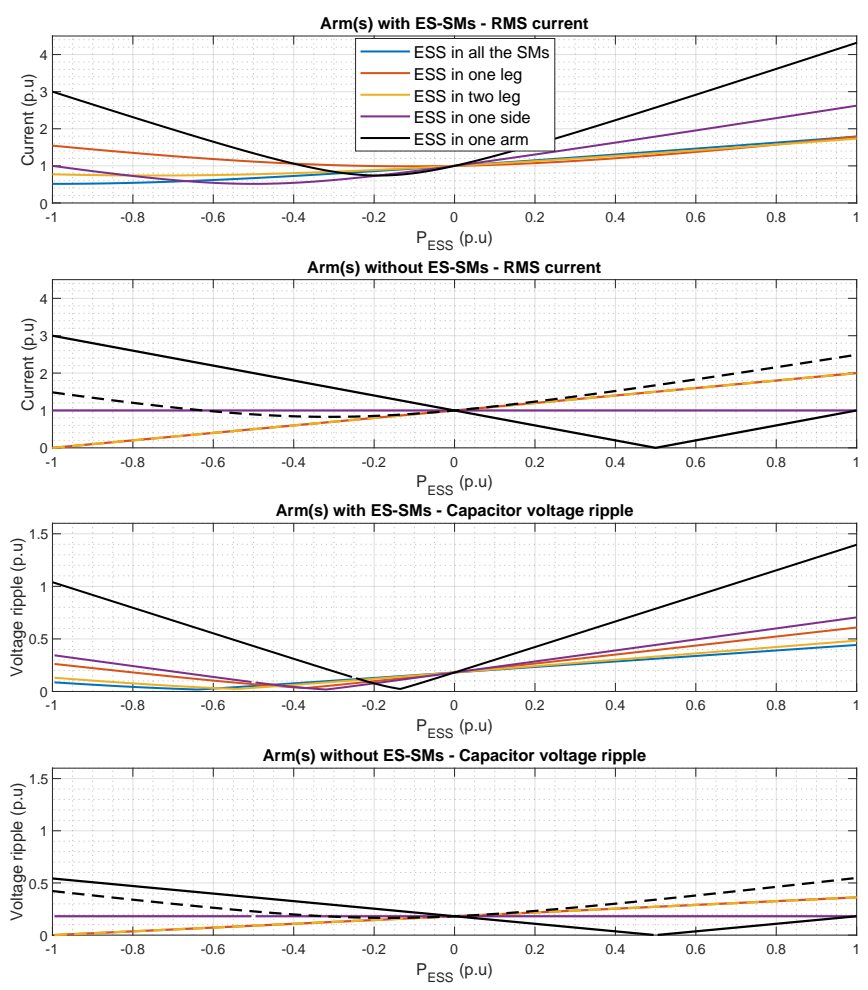

Fig. 5. RMS arm current, Capacitor voltage ripple in the converter assuming unequal ESS distribution - Inverting de Power

behaviour. Therefore, yellow and orange lines are mixed up. The explanation is made for one phase.

Considering phase $a$ has ES-SMs, a power transfer between individual phase legs is required. The dc part of the circulating current is used to transfer energy, $I_{c i r c_{x}}^{d c}$. Because the power injected in phase $a$ must be evenly distributed among arms, the standard legs $b$ and $c$ receive an equal amount of power (i.e $I_{\text {circ }_{b}}^{d c}=I_{\text {circ }_{c}}^{d c}=-I_{\text {circ }_{a}} / 2$ ). Note those currents only cause a positive or negative dc offset depending on the legs. 

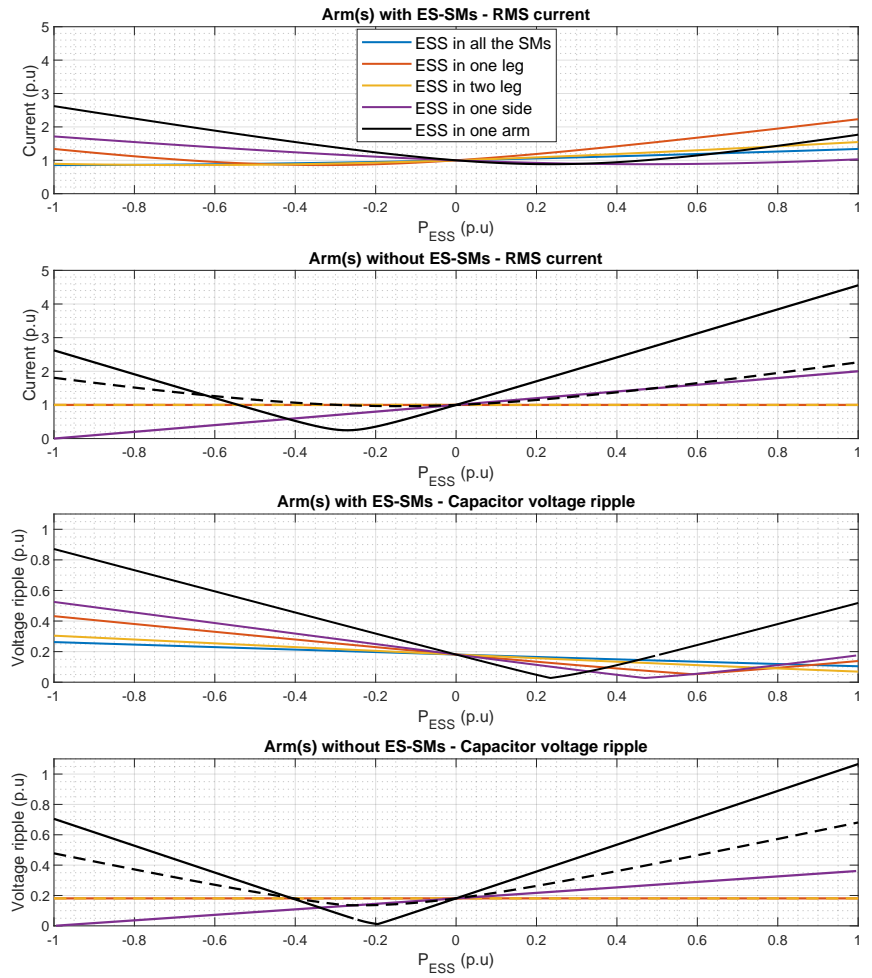

Fig. 6. RMS arm current, Capacitor voltage ripple in the converter assuming unequal ESS distribution - Rectifying ac Power

In rectifier mode, the phases without ES-SMs experience no change. The ac input power remains fixed and the circulating current compensates the changes in dc current from the $\mathrm{dc}$ bus to maintain the dc component in each individual phase leg constant. As a result, capacitor voltage ripple also does not change.

When increasing the power the ESS has to absorb in inverter mode, standard phase legs have less contribution. The dc offset leads to a zero current in these phases while all the dc current from the dc grid, $I_{d c}$, must be supported by the phase with ES-SMs.

\section{B. Integrating ESS in one side of the converter}

By integrating ESSs in one side of the converter (purple line), the power transfer within each leg is done by the ac part of the circulating current, $i_{\text {circ }}^{a c}(t)$. A phase shift of $\psi=$ $180^{\circ}$ is assumed to maximise the power transfer without any residual reactive power (9), (10).

Considering an inverter mode, if the ac output rises $\left(P_{E S S}>0\right)$, the ac component of the arm current increases. However, the circulating ac current is phase aligned with the top arms and in opposition with the bottom arms. Those currents tend to add each other in the upper arms and cancel them in the lower arms. If the ac power decreases $\left(P_{E S S}<0\right)$, the dc current that power SMs from the dc grid is unchanged and is still equally distributed among the phase legs. But, in the lower side, the circulating current compensates the missing part of the ac current. It explains why the arms without ES-SMs expect no changes in this mode. Finally, it also decreases the RMS current in the upper side before returning to nominal value when the whole input power is absorbed. Even though capacitors voltage ripple follows a same trend, the voltage deviation is more important. A value close from zero is also observed for $P_{E S S} \approx-0.35$ p.u. It corresponds to a situation where the intrinsic oscillations of the converter and the extra oscillations induced by the circulating current erase each other in SM capacitor current, (12). Figure.7 shows the obtained results. Note, this situation also happens in the other configurations.

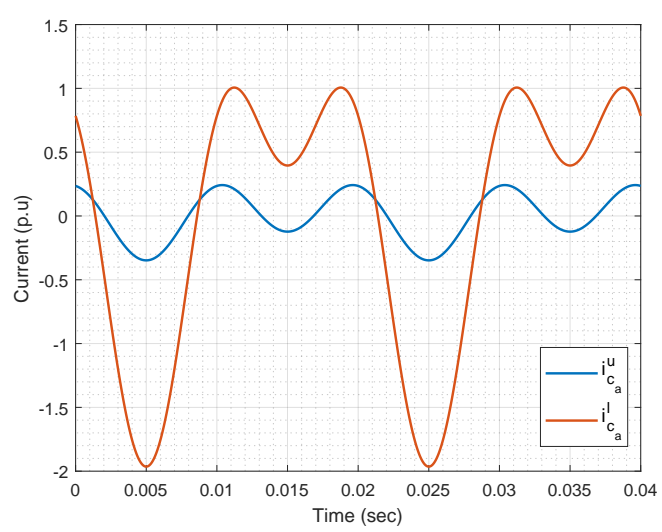

Fig. 7. Submodule capacitor current for an MMC with ES-SMs in the upper side of the converter and $P_{E S S}=-0.35$ p.u during inverter operation

In rectifier mode, the lower arms have to be considered now. Roles are reversed. With increasing $P_{d c}$ (i.e $P_{E S S}$ ), the additional circulating ac current leads to a slight drop in upper arm RMS current and a decrease in capacitor voltage ripple. However, it is counterbalanced in the lower arms without ESSMs. The additional circulating ac current is added to the existing arm ac component and so increases the resulting RMS arm current and capacitor voltage ripple magnitudes.

\section{Integrating ESS in one arm}

This situation is a combination of a power transfer among phase legs and between arms within the phase with ES-SMs. Both the $\mathrm{dc}$ and the ac part of the circulating current are needed. However, no vertical power transfer must occur in the phase legs $b, c$ which contain no ES-SMs. By controlling the circulating current in these phases in quadrature with the respective lower and upper arm voltages, only reactive power can be transferred whilst (6) is still respected [14].

Results show that this configuration increases significantly the current and voltage ripple values as in the arm with ESSMs as in the opposite arm (black line) or the remaining legs (black dotted line) without ES-SMs. Large circulating currents are required. It is also the case where the load distribution differs the most within the converter. Fig.8 represents the SM capacitor currents within the MMC arms when only one arm is equipped with ES-SMs. It clearly shows this disparity. 


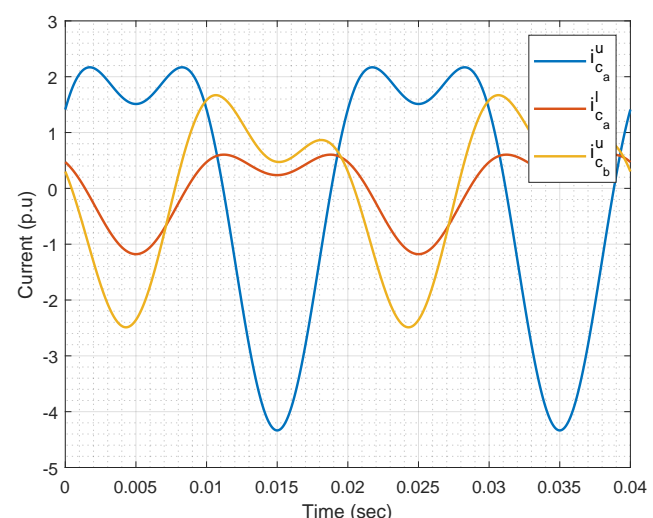

Fig. 8. Submodule capacitor current for an MMC with ES-SMs in the upper arm of phase $a$ of the converter and $P_{E S S}=0.2$ p.u during inverter operation

\section{Simulation}

To verify the previous analysis, an MMC reduced order average model with a storage function was developed in Matlab/Simulink [18]. Each MMC arm is represented by an ideal SM with an equivalent capacitor. It is assumed that all the SM capacitors are strictly identical. Consequently, the voltage at its terminal, $\Sigma u_{c_{x}}^{u, l}$, is the sum of all the SM capacitor voltages. All the SMs are modelled by means of a state variable model with an ESS connected to it that behaves as a current source. This latter can be activated or not depending on the required configuration. The $\mathrm{dc}$ and the ac grids are modelled as ideal voltage sources.

This model allows to decouple the MMC into two ac and dc sub-systems that can be controlled independently. The low level control of the MMC, which aims to select the SMs that should be inserted to synthesize the desired arm voltage, is not taken into account [19]. Only the high level control is considered. An overview of the control scheme is depicted in Fig.9. The control structure is based on an inner and an outer loop.

The inner loop regulates the grid currents within the converter. Considering that an MMC is a 3-phase system from the ac point of view, the regulation of the ac currents is achieved in a $d q$ rotating frame using a Phase Lock Loop (PLL) to follow the grid voltage. While the dc current are controlled in a classical stationary frame. The outer loop helps to control the inputs of the inner layer but also the total internal energy stored, $W_{M M C}$. In order to regulate the energy distribution within the converter, three different energy controllers are implemented.

Global energy management: An MMC can be seen as an energy buffer whose the energy variation is driven by the power mismatch between the dc and ac side (15). A controller focus on the overall energy content is needed to compensate the error before the energy level becomes unsatisfactory.

$$
\frac{d W_{M M C}}{d t}=P_{d c}-P_{a c}
$$

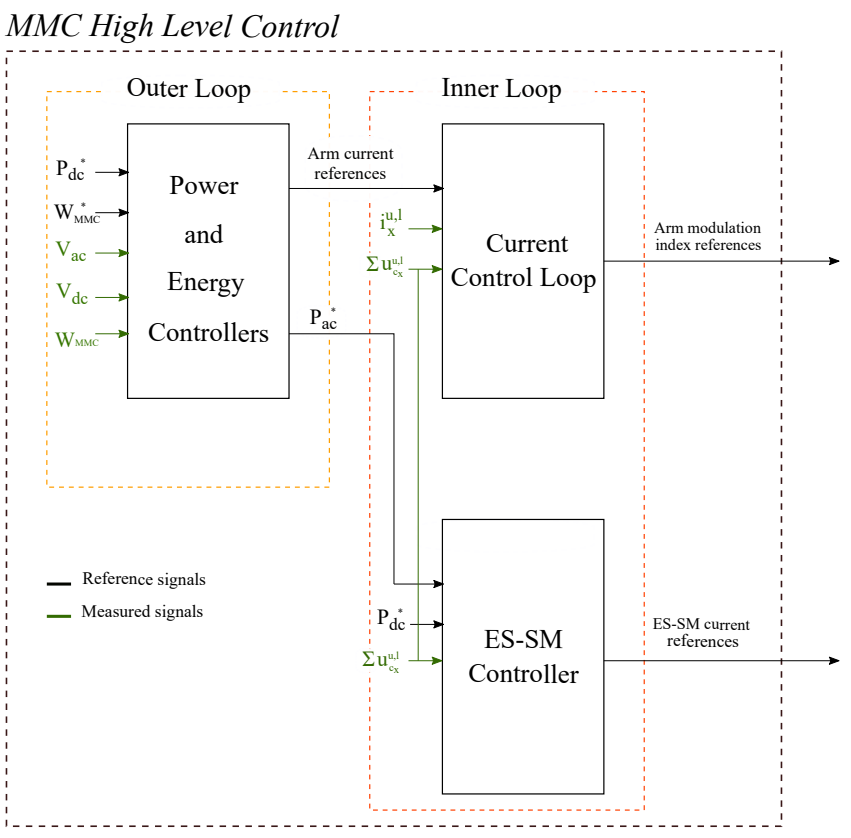

Fig. 9. General schematic diagram of the high level control scheme for a MMC with ESSs

Phase energy balancing control: As stated before, the internal energy stored should be well distributed among the six arms. Consequently, each leg must firstly store one third of the total energy. A controller is required to ensure adequate energy level among legs and enable horizontal power transfer.

Inter-arm energy balancing control: During one period the upper and lower arm inherently exchange energy. However, the energy deviation between the two arms must remain zero. To maintain the power balance within each individual phase leg, a second controller is necessary to allow vertical power exchange between the upper and the lower arm.

Finally, it has been chosen to regulate the desired energy level of the MMC by adjusting the ac power and let the dc power track its reference.

Because of the cascaded control structure of the converter, the inner loop must be faster than the outer loop to have enough time to converge. The different PI controllers have been designed to ensure this minimum response time and make the two loops dynamically independent. More details on the model and the control variables are available in [16]. An additional loop was added to control the power exchanged by the ES-SMs. On the basis of a measure of the equivalent SM capacitor voltage, $\Sigma u_{c_{x}}^{u, l}$, plus the power mismatch between the $\mathrm{dc}$ and ac grids, a current reference is provided to the dc-dc converter.

Table I gives specifications of the MMC converter. Simulations results (Fig.10) are those of an MMC with only the upper arm of phase $a$ equipped with ES-SMs (Fig.3(c)) in inverter mode. This configuration has been chosen to show the aptitude of the converter to achieve both vertical and horizontal power transfer. A $100 \mathrm{MW}$ energy storage power is considered. 
(a)

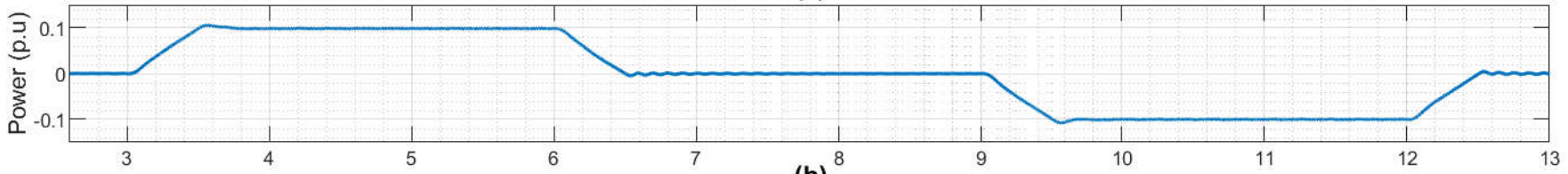

(b)

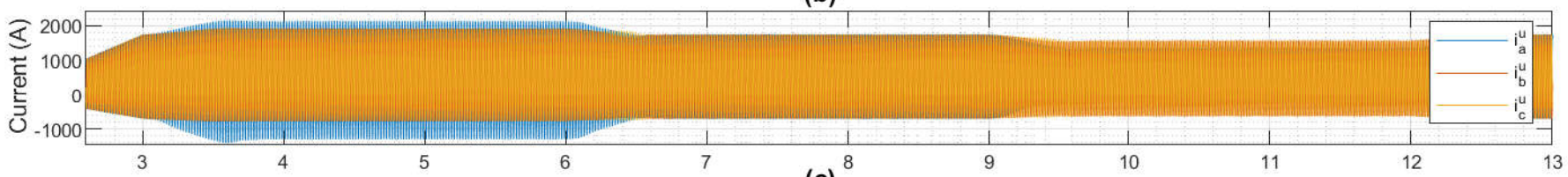

(c)

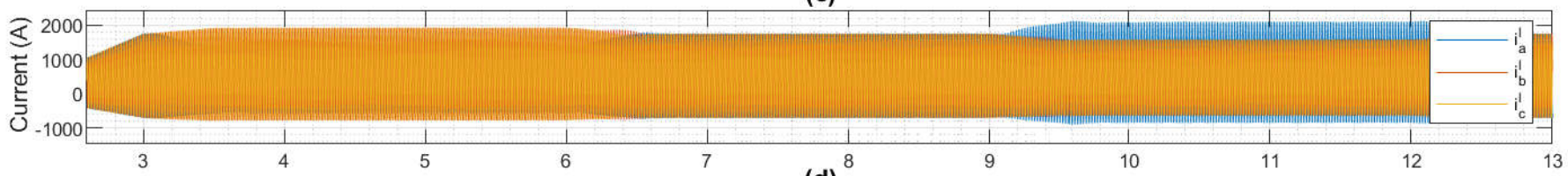

(d)

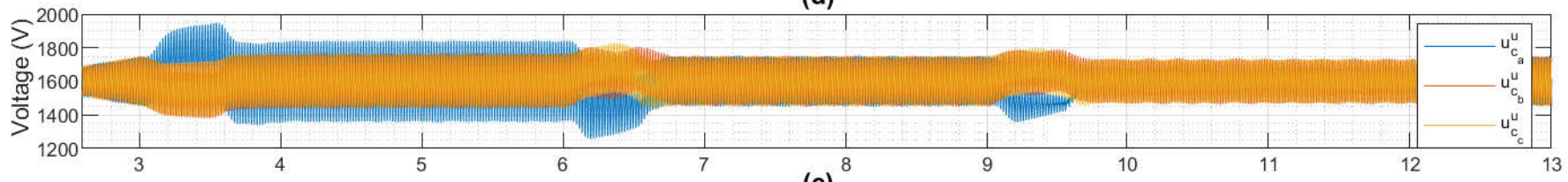

(e)
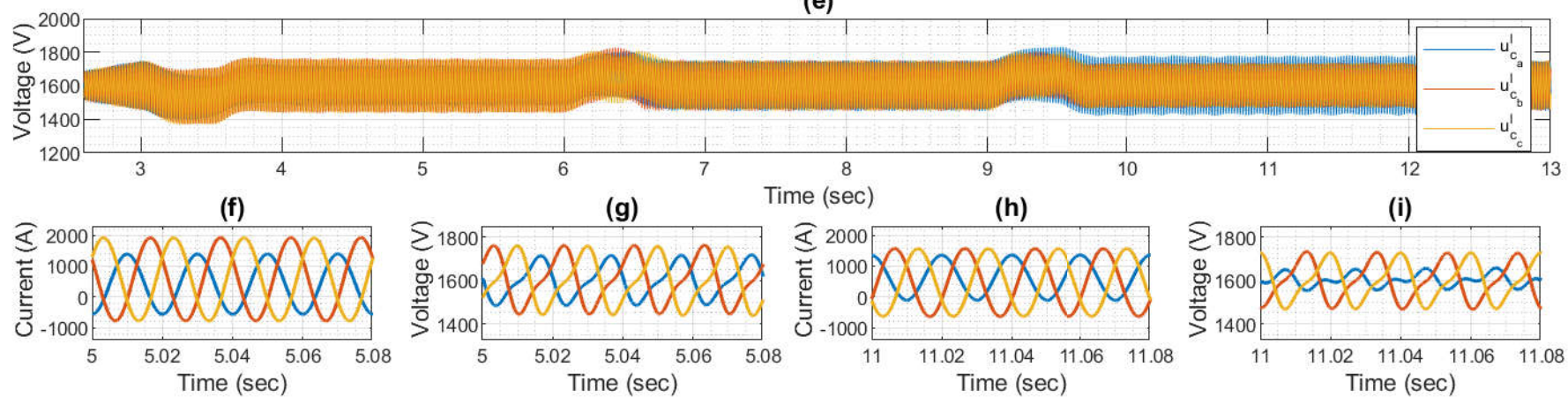

(g)

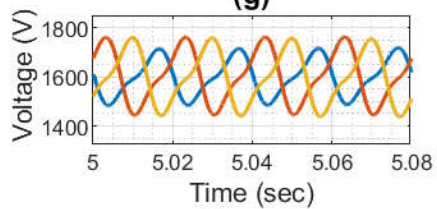

Time (sec)

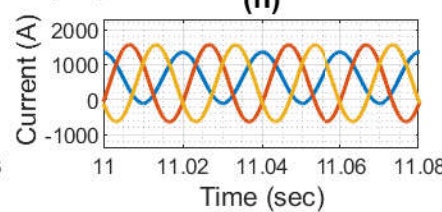

(i)

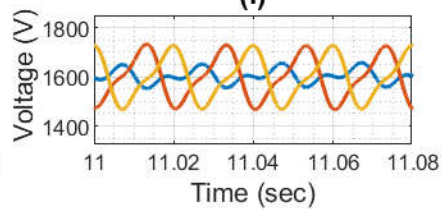

Fig. 10. Modular Multilevel Converter with ESSs connected to the upper arm in phase A. From top to bottom : (a) Difference between the AC and DC side powers. (b) Upper arm currents. (c) Lower arm currents. (d) Upper arm SM voltages. (e) Lower arm SM voltages. (f) Zoom on lower arm currents. (g) Zoom on lower arm SM voltages (h) Zoom on upper arm currents. (i) Zoom on upper arm SM voltages

Different loading conditions has been tested through three operating points by varying the ac power.

TABLE I

MODEL PARAMETERS

\begin{tabular}{lr}
\hline Parameters & Values \\
\hline Nominal Power & $1000 \mathrm{MVA}$ \\
Line to line AC voltage & $333 \mathrm{kV}$ \\
DC voltage & $\pm 320 \mathrm{kV}$ \\
Number of SMs per arm & 400 \\
SM Capacitance & $10 \mathrm{mF}$ \\
Average SM voltage & $1600 \mathrm{~V}$ \\
\hline
\end{tabular}

During the simulations, SM voltage is properly controlled around a mean value of $1600 \mathrm{~V}$ as shown Fig.10(d)(e). The converter is able to follow the change of operating point (Fig.10(a)). At normal load condition, the converter is well balanced and no circulating current is required. As a results arm currents (and capacitor voltage ripple) are strictly identical among arms.
An example of an MMC in overload operation is shown from $t=3 \mathrm{~s}$ to $t=6 \mathrm{~s}$. The converter compensates an increase of power at the ac side. During this time interval, the arm current in the upper arm in phase $a, i_{a}^{u}$, increases more than others but there is also a slight rise in the remaining legs as observed Fig.10(b). As the overall arm currents goes up, the voltage ripple on the SM capacitors changes. The peak to peak deviation becomes more significant in the upper arm with ES-SMs, $u_{c_{a}}^{u}$, and less restrictive in the opposite arm, $u_{c_{a}}^{l}($ Fig.10(d) (g)).

Then, from $t=9 \mathrm{~s}$ to $t=12 \mathrm{~s}$, the converter has to absorb an excess of power via the ES-SMs. During this cycle, the RMS current in the arm with storage function drops, $i_{a}^{u}\left(\right.$ Fig.10(b)(h)) just as the capacitor voltage ripple, $u_{c_{a}}^{u}$ (Fig.10(d)(i)). It can be noted that the current in the opposite arm increases, $i_{a}^{l}$, just like the capacitor voltage ripple, $u_{c_{a}}^{l}$. While the remaining legs keep a behavior close as in normal operation mode. In a general manner, the MMC performs as expected Fig.5. 
Fig.11 shows the comparison of the capacitor voltage obtained by the simulation in the upper arm of phase $a$ during overload condition and the one derived analytically in the previous section. As it can be observed, the estimated waveform matches with the simulation. The previously derived analytic expressions have been validated for all the case studies. These formulae can help for designing an MMC with ESSs in a future work.

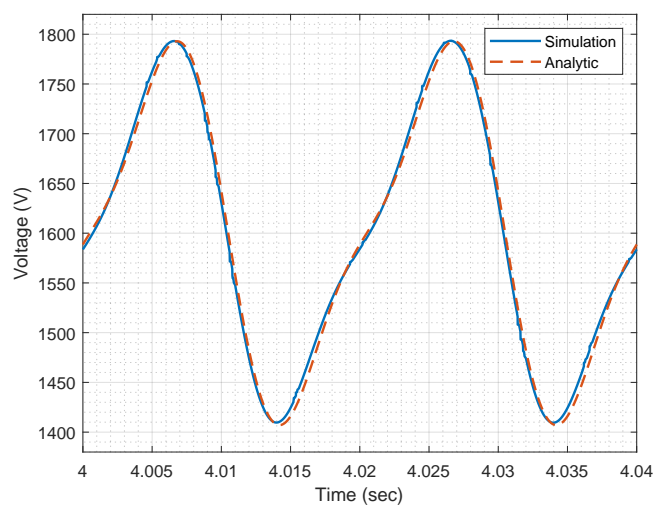

Fig. 11. Comparison of the estimation of the capacitor voltage with simulation results

\section{CONCLUSION AND OUTLOOKS}

In this paper, the integration of split storage within an MMC for ancillary services have been discussed. The concept of using circulating currents to ensure the proper energy balancing of the converter have been described. Simulation results have been presented to demonstrate its feasibility and to validate the theoretical analysis. The worst case, when only one arm of the converter is equipped with ES-SMs, has been chosen to demonstrate the feasibility.

It has been shown that RMS arm currents and capacitor voltages become the limiting factors when trying to reduce the number of SMs with ESSs. A one size fits all solution does not exist. Selecting the right configuration mainly depends on the application but above all of the power conversion system that will be implemented between the ESS unit and the SM capacitor.

However, it can be judicious to try to avoid the use of circulating current. And certainly, the concept of an arm with a fraction of SMs [15] can be interesting. Nonetheless, it causes additional challenges such as the need of SMs with different capacitors sizes because of different energy deviations experienced.

\section{ACKNOWLEDGMENT}

This work was supported by a grant overseen by the French National Research Agency (ANR) as part of the 'Investissements d'Avenir" Program (ANE-ITE-002-01).

\section{REFERENCES}

[1] European Comission, "Com (2011) 112 - A roadmap for moving to a competitive low carbon economy in 2050," 2011.

[2] D. S. Kirschen and G. Strbac, Fundamentals of power system economics. John Wiley \& Sons, 2004.
[3] P. Fairley, "DC versus AC: The second war of currents has already begun [in my view]," IEEE Power and energy magazine, vol. 10, no. 6, pp. 104-103, 2012.

[4] A. Lesnicar and R. Marquardt, "An innovative modular multilevel converter topology suitable for a wide power range," in Power Tech Conference Proceedings, 2003 IEEE Bologna, vol. 3. IEEE, 2003, pp. 6-pp.

[5] L. Maharjan, S. Inoue, and H. Akagi, "A transformerless energy storage system based on a cascade multilevel PWM converter with star configuration," IEEE Transactions on Industry Applications, vol. 44, no. 5, pp. 1621-1630, Sept 2008.

[6] M. Vasiladiotis, "Modular Multilevel Converters with Integrated Split Battery Energy Storage," Ph.D. dissertation, STI, Lausanne, 2014.

[7] N. Kawakami, S. Ota, H. Kon, S. Konno, H. Akagi, H. Kobayashi, and N. Okada, "Development of a 500-kW modular multilevel cascade converter for battery energy storage systems," IEEE Transactions on Industry Applications, vol. 50, no. 6, pp. 3902-3910, 2014.

[8] B. Novakovic and A. Nasiri, "Modular multilevel converter for wind energy storage applications," IEEE Transactions on Industrial Electronics, 2017.

[9] R. Alvarez, M. Pieschel, H. Gambach, and E. Spahic, "Modular multilevel converter with short-time power intensive electrical energy storage capability," in 2015 IEEE Electrical Power and Energy Conference (EPEC), Oct 2015, pp. 131-137.

[10] T. Soong and P. W. Lehn, "Evaluation of emerging modular multilevel converters for BESS applications," IEEE Transactions on Power Delivery, vol. 29, no. 5, pp. 2086-2094, Oct 2014.

[11] I. Trintis, S. Munk-Nielsen, and R. Teodorescu, "A new modular multilevel converter with integrated energy storage," in IECON 201137th Annual Conference on IEEE Industrial Electronics Society. IEEE, 2011, pp. 1075-1080.

[12] F. Errigo, P. Venet, L. Chedot, and A. Sari, "Optimal supercapacitor pack sizing for modular multilevel converter with integrated energy storage system," in 2018 IEEE International Conference on Industrial Technology (ICIT), Feb 2018, pp. 1760-1766.

[13] G. Konstantinou, J. Pou, D. Pagano, and S. Ceballos, "A hybrid modular multilevel converter with partial embedded energy storage," Energies, vol. 9, no. 12, p. 1012, 2016.

[14] G. Henke and M.-M. Bakran, "Balancing of modular multilevel converters with unbalanced integration of energy storage devices," 2016 18th European Conference on Power Electronics and Applications (EPE'16 ECCE Europe), pp. 1-10, 2016.

[15] P. Judge and T. Green, "Modular multilevel converter with partially rated energy storage with intended applications in frequency support and ancillary service provision," IEEE Transactions on Power Delivery, pp. 1-1, 2018.

[16] K. Shinoda, A. Benchaib, J. Dai, and X. Guillaud, "Virtual capacitor control: Mitigation of DC voltage fluctuations in MMC-based HVDC systems," IEEE Transactions on Power Delivery, vol. 33, no. 1, pp. 455-465, Feb 2018.

[17] J. Peralta, H. Saad, S. Dennetière, J. Mahseredjian, and S. Nguefeu, "Detailed and averaged models for a 401-level MMC-HVDC system," IEEE Transactions on Power Delivery, vol. 27, no. 3, pp. 1501-1508, 2012.

[18] A. Antonopoulos, L. Angquist, and H.-P. Nee, "On dynamics and voltage control of the modular multilevel converter," in Power Electronics and Applications, 2009. EPE'09. 13th European Conference on. IEEE, 2009, pp. 1-10.

[19] A. Zama, S. A. Mansour, D. Frey, A. Benchaib, S. Bacha, and B. Luscan, "A comparative assessment of different balancing control algorithms for modular multilevel converter (MMC)," in 2016 18th European Conference on Power Electronics and Applications (EPE'16 ECCE Europe), Sep. 2016, pp. 1-10. 